\title{
Characterization and formulation of a new eco-friendly hydraulic binder based on combination of inorganic and organic admixtures
}

\author{
M.H.R. KHUDHAIR ${ }^{1,2,3, *}$, M. S. EL YOUBI ${ }^{3}$, A.ESSAMRI ${ }^{1}$, A. ELHARFI ${ }^{1}$ \\ ${ }^{1}$ Laboratory of Agro Resources Polymers and Process Engineering (LAPPE), Team of Macromolecular \& \\ Organic Chemistry, Faculty of Sciences, Ibn Tofail University, BP 133, 14000, Kenitra, Morocco. \\ ${ }^{2}$ Laboratory of Cement and Quality Control of Amran Cement Plant of Yemen. \\ ${ }^{3}$ Laboratory of Chemistry of Solid State, Faculty of Science, Ibn Tofail University, Kenitra, Morocco. \\ *Corresponding author: khudhair.mohammed65@gmail.com
}

\begin{abstract}
This work aims to valorize a mineral and natural resources such as the Limestone Fillers (F-Lime) and the Natural Pozzolan (PN) by incorporating them into the formulation matrix of cement or concrete. In order to minimize the $\mathrm{CO}_{2}$ emissions into the atmosphere, to reduce the energy and raw materials consumption and as well as, to improve the physical and mechanical properties in fresh cement paste and of mortar or concrete in the hardened state. In this present manuscript, we substituted the clinker by the combination between the F-Lime and NP at $40 \%$ by weight of cement with steps of $5 \%$ with the admixture of superplasticizers. The influences of the incorporation of these additions on physical and mechanical properties of mortar or concrete in the fresh cement paste and hardened state were evaluated. The obtained results by different formulations elaborated to show that the replacement a part of clinker by the mixing of F-Lime and PN has produced a new hydraulic binder eco-friendly and durable with improved physicochemical, physical and mechanical properties These results show that we have succeeded to manufacture, characteristic and formulated of new ecofriendly hydraulic binder and sustainable with improved physical, chemical, and mechanical properties while minimizing greenhouse gas emissions on one hand and the reducing the energy raw materials consumption on the other hand.
\end{abstract}

Keywords: New eco-friendly hydraulic binder, Inorganic admixture, Organic admixture, Limestone Fillers, Natural Pozzolan, chemical admixture, Superplasticizers, Physical properties, Porosity, Capillary absorption, Compressive strength, Durability.

\section{Introduction}

The Yemen's country contains considerable amounts of mineral admixtures such as the natural pozzolan (PN); of volcanic origin from the DifanAmran deposit north of Sana'a in Yemen, $[1,2]$ and the limestone fillers (F.Lime), which is found in several regions of Yemen, namely, Hadramaout, El Maharah, Sana'a, Amran, Etc . [3, 4].

The valorization of these mineral admixtures by incorporation them as an additive in fabrication of cement and various types of concretes has both benefits economic and environmental; to reduce the energy consumption and raw materials used during the manufacture of clinker or cement on one hand and to minimize the greenhouse gas emissions into the atmosphere on the other hand [5-7].

These admixtures by their fineness and their reactivity in presence of cement lead to significant changes in physical and mechanical properties of mortars or concrete in fresh cement paste and hardened state [8-12]. The presence of inorganic or organic admixtures (F.Lime, PN or superplasticizers) in cement or mortar (concrete) matrix modifies the structure of granular skeleton (granular effect) and the friction between the solid components in liquid phase [13-16]. In the same way, during the setting and hardening [17-20], the additions particles interact in cement hydration process while modifying the structure of the hydrated products and for some may react chemically (effects physical-chemical and microstructure) at cementitious environments, in order to form of a new hydrated products which have an additional binding character (improvement of physical properties and mechanical performances).

The interaction between the organic and inorganic admixtures makes it possible to increase the hydration rate of mortars or concretes while modifying the W/C ratio and to improve the mechanical performance [2,21-23]. This improvement finally influences the mechanical of compressive strength. Indeed, when the molecules of admixtures of superplasticizers SP103 are 
introduced into a suspension of concrete formulated by the combination between the F.Lime and the NP, a large part of them is fixed to the surface of the cement particles (adsorption)[16,24-25].

In this work, different formulations have been elaborated while partially substituting the clinker by the combination between limestone fillers and natural pozzolan at $40 \%$ by weight of cement with a step of $5 \%$, in the presence of admixtures of superplasticizers of high water reducer and retarder SP103 of setting. The influence of the incorporation

\section{Materials and methods}

\subsection{Materials}

\subsubsection{Cement}

The type of cement used in this work is (CMI42.5), this is a Portland cement as a resulting of simultaneous grinding at $(95 \%)$ of clinker and $(5 \%)$ of gypsum according to the standard EN 196-1. The chemical compositions (gypsum and cement) and mineralogical (clinker) are presented in Table 1 and 2.

Table 1: Elementary chemical compositions of clinker, gypsum, and cement in weight of atomic

\begin{tabular}{|l|l|l|l|}
\hline Chemical name & Chemical formula & Gypsum & Cement \\
\hline Lime & $\mathrm{CaO}$ & 33.40 & 61.29 \\
\hline Silica & $\mathrm{SiO}_{2}$ & 0.70 & 19.99 \\
\hline Alumina & $\mathrm{Al}_{2} \mathrm{O}_{3}$ & 0.36 & 5.57 \\
\hline Ferrite & $\mathrm{Fe}_{2} \mathrm{O}_{3}$ & 0.09 & 2.85 \\
\hline Magnesia & $\mathrm{MgO}$ & 0.63 & 1.89 \\
\hline Sulfur trioxide & $\mathrm{SO}_{3}$ & 47.20 & 3.22 \\
\hline Potassium oxide & $\mathrm{K}_{2} \mathrm{O}$ & 0.03 & 1.15 \\
\hline Sodium oxide & $\mathrm{Na}_{2} \mathrm{O}$ & 0.10 & 0.20 \\
\hline Chlorine & $\mathrm{Cl}^{-}$ & 0.01 & 0.02 \\
\hline
\end{tabular}

Table 2: Mineralogical composition of clinker

\begin{tabular}{|l|l|l|l|}
\hline Chemical name & $\begin{array}{l}\text { Mineral } \\
\text { name }\end{array}$ & $\begin{array}{l}\text { Cement } \\
\text { nomenclature }\end{array}$ & Content \\
\hline Tricalcium silicate & Alite & $\mathrm{C}_{3} \mathrm{~S}$ & 47.70 \\
\hline Dicalcium silicate & Balite & $\mathrm{C}_{2} \mathrm{~S}$ & 25.10 \\
\hline Tricalcium aluminate & Aluminate & $\mathrm{C}_{3} \mathrm{~A}$ & 10.40 \\
\hline $\begin{array}{l}\text { Tetracalcium } \\
\text { Aluminoferrite }\end{array}$ & Ferrite & $\mathrm{C}_{4} \mathrm{AF}$ & 9.10 \\
\hline
\end{tabular}

\subsubsection{Inorganic additions}

\section{* Limestone Fillers (F.Lime)}

They are mineral materials which spread in several regions in Yemen, such as Hadramaout, Sana'a, Amran and etc.

\section{- Natural pozzolan (PN)}

The natural pozzolan (PN) used is of volcanic origin, extracted from Difan-Amran's deposit of Yemen located in the north of Sana'a.

\section{Physical-chemical characteristics}

The results of the analysis by X-ray fluorescence (XRF) of F.Lime and PN after crushing, drying in the oven for 24 hours at a temperature of $50{ }^{\circ} \mathrm{C}$ and grinding are represented in the Table 3. of these admixtures on physical and mechanical properties in fresh cement paste and hardened state were studied. The obtained results from the various formulations elaborated show that the substitution a part of clinker by the mixing of F.Lime the PN in the presence of mixtures of superplasticizers enabled us to production of a new hydraulic binder with improved physicochemical, physical and mechanical properties, while reducing the cost of production, minimizing $\mathrm{CO}_{2}$ emissions to the atmosphere, reducing the use of mixing water.

Table 3: Elementary chemical compositions of F.Lime and $\mathrm{PN}$ in weight of atomic

\begin{tabular}{|c|c|c|}
\hline Content (\%) & F.Lime & PN \\
\hline $\mathbf{C a O}$ & 54.96 & 8.8 \\
\hline $\mathbf{S i O}_{\mathbf{2}}$ & 0.62 & 41.43 \\
\hline $\mathbf{A l}_{\mathbf{2}} \mathbf{O}_{\mathbf{3}}$ & 0.12 & 16.16 \\
\hline $\mathbf{F e}_{\mathbf{2}} \mathbf{O}_{\mathbf{3}}$ & 0.16 & 9.41 \\
\hline $\mathbf{M g O}$ & 0.41 & 4.79 \\
\hline $\mathbf{S O}_{\mathbf{3}}$ & 0.08 & 0.128 \\
\hline $\mathbf{K}_{\mathbf{2}} \mathbf{O}$ & 0.01 & 0.9 \\
\hline $\mathbf{N a}_{\mathbf{2}} \mathbf{O}$ & 0.00 & 3.47 \\
\hline $\mathbf{C l}^{-}$ & 0.00 & 0.04 \\
\hline $\mathrm{LOI}$ & 43.63 & 14.87 \\
\hline
\end{tabular}

The physical properties of limestone fillers and natural pozzolan have given in Table 4.

Table 4: Physical properties of F.Lime and PN

\begin{tabular}{|c|c|c|c|c|}
\hline $\begin{array}{c}\text { Name of } \\
\text { addition }\end{array}$ & Color & $\begin{array}{l}\text { Size of } \\
\text { particles }(\mu \mathrm{m})\end{array}$ & $\begin{array}{l}\text { Specific surface } \\
\text { Blaine }\left(\mathrm{cm}^{2} \cdot \mathrm{g}^{-1}\right)\end{array}$ & $\begin{array}{l}\text { Density } \\
\left(\mathrm{g} \cdot \mathrm{cm}^{-3}\right)\end{array}$ \\
\hline F.Lime & White & 50 & 4776 & 2.13 \\
\hline PN & Black & 60 & 4576 & 2.81 \\
\hline
\end{tabular}

\subsubsection{Chemical admixtures}

The admixtures of superplasticizers are polymers in liquid form, especially synthesized for the concrete industry. These superplasticizers are delivered by the company CONMIX Ltd of Sharjah, United Arab Emirates. They are incorporated during the mixing of concrete at doses equal from $0.5 \%$ to $4 \%$ by weight of cement with a step of $0.5 \%$. In this work, we used a High Range Water Reducing And Accelerating Superplasticiser SP103, Figure 1.

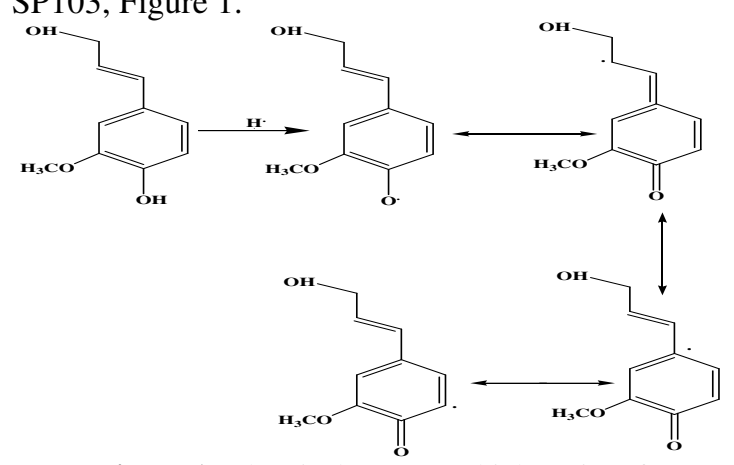

Figure 1: Chemical structure, high purity of lignosulfonate 


\subsubsection{Mixing water}

The water used to mix the mortar or concrete is tap water. The main characteristics of these waters are summarized in Table 5.

Table 5: Main features of the mixing water

\begin{tabular}{|l|c|c|}
\hline Components & Unity & Values \\
\hline $\mathbf{p H}$ & - & 7.00 \\
\hline Turbidity & $\mathrm{mg} / \mathrm{l}$ & 450.00 \\
\hline $\mathbf{C O}_{\mathbf{3}}{ }^{-2}$ & $\mathrm{mg} / \mathrm{l}$ & 216.00 \\
\hline $\mathbf{H C O}_{\mathbf{3}}^{-}$ & $\mathrm{mg} / \mathrm{l}$ & 0.00 \\
\hline $\mathbf{C a}^{+2}$ & $\mathrm{mg} / \mathrm{l}$ & 56.40 \\
\hline $\mathbf{M g}^{+2}$ & $\mathrm{mg} / \mathrm{l}$ & 52.40 \\
\hline Conductivity & $\mu \mathrm{S} / \mathrm{cm}$ & 692.00 \\
\hline
\end{tabular}

\subsubsection{Sand}

To make our mortar and /or concrete, we used standard sand according to the norm EN 196-1,

\subsection{Methods}

To achieve the objective of our study, we have prepared a reference mortar without additions whose compositions are inspired by that of the normal mortar defined by the norm EN 196-1, with a quantity of water adjusted to obtain a reference consistency. And other mortar with mineral additions (PN+ F.Lime) and superplasticizers SP103, always keeping the standardized consistency fixed. For each mortar having acquired this consistency, we have prepared prismatic specimens with dimensions $(40 \times 40 \times 160) \mathrm{mm}^{3}$. The compressive strengths were measured at a young age ( 2 days), in median age (7 days) and long-term (28 days) using a bending test machine to break the specimen into two halves and each party is responsible the subject of compressive using a hydraulic testing machine. The value of the resistance is considered as the average of the crushing stress of three test pieces (6 halves).

The compressive strength was calculated using the equation (1).

Compressive strength $=\frac{\text { Load , in "N" }}{\text { Area, in "mm }{ }^{2 n}} ; \mathrm{MPa}$ Equation 1

The various formulations tests carried out by maintaining the content of gypsum $5 \%$ by weight of a total of cement with $40 \%$ of the mixture of Fillers Limestone (F. Lime) and Natural Pozzolan (PN) are presented in the Tables 6 and 7.

\section{Results and discussion}

\subsection{Influence on Physicochemical properties}

The Table 8 shows the physicochemical properties of fresh cement paste formulated with combination of F.Lime and PN.

Table 8: Physicochemical properties of cement paste

\begin{tabular}{|c|c|c|c|c|c|c|}
\hline \multirow{2}{*}{$\begin{array}{l}\text { Content } \\
\text { (\%) }\end{array}$} & \multirow{2}{*}{$\begin{array}{l}\text { Density } \\
\text { "g } \mathrm{cm}^{-3 "}\end{array}$} & \multirow{2}{*}{$\begin{array}{l}\text { Fineness } \\
" \mathrm{~cm}^{2} \cdot \mathrm{g}^{-1 "}\end{array}$} & \multicolumn{2}{|c|}{ Setting time 'man' } & \multirow{2}{*}{$\mathrm{W} / \mathrm{C}$} & \multirow{2}{*}{ Expansion } \\
\hline & & & Initial & Final & & \\
\hline 1 & 3.02 & 4050 & 40 & 80 & 0.54 & 0.5 \\
\hline
\end{tabular}

delivered by the new French company of the Littoral. Its particle size analysis is illustrated in Figure 2.

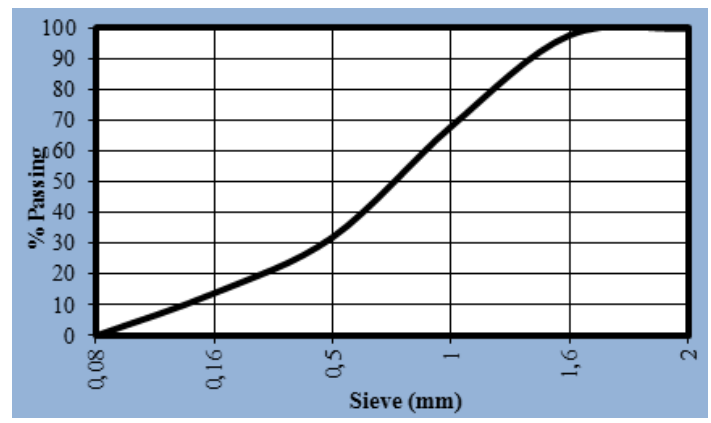

Figure 2: Curve granulometric of sand

According to the granulometric analysis presented in Figure 2, we found that the sand grains used are distributed in a systematic way according to the specifications of the norm EN 196 - 1.

Table 6: Formulation matrix of cement paste

\begin{tabular}{|c|c|c|c|c|}
\hline Content & Cement (\%) & F.Lime (\%) & PN (\%) & W/C Report \\
\hline $\mathbf{1}$ & 60 & 40 & 0 & 0.32 \\
\hline $\mathbf{2}$ & 60 & 35 & 5 & 0.308 \\
\hline $\mathbf{3}$ & 60 & 30 & 10 & 0.292 \\
\hline $\mathbf{4}$ & 60 & 25 & 15 & 0.28 \\
\hline $\mathbf{5}$ & 60 & 20 & 20 & 0.27 \\
\hline $\mathbf{6}$ & 60 & 15 & 25 & 0.256 \\
\hline $\mathbf{7}$ & 60 & 10 & 30 & 0.246 \\
\hline $\mathbf{8}$ & 60 & 5 & 35 & 0.234 \\
\hline $\mathbf{9}$ & 60 & 0 & 40 & 0.21 \\
\hline
\end{tabular}

Table 7: Formulation matrix of mortar or concrete in the hardened state

\begin{tabular}{|c|c|c|c|c|c|}
\hline Content & $\begin{array}{c}\text { Cement } \\
(\mathbf{\%})\end{array}$ & $\begin{array}{c}\text { F.Lime } \\
(\boldsymbol{\%})\end{array}$ & $\begin{array}{c}\text { PN } \\
(\boldsymbol{\%})\end{array}$ & $\begin{array}{c}\text { Sand } \\
(\mathbf{g})\end{array}$ & $\begin{array}{c}\text { W/C } \\
\text { Report }\end{array}$ \\
\hline 1 & 60 & 40 & 0 & 1350 & 0.54 \\
\hline 2 & 60 & 35 & 5 & 1350 & 0.52 \\
\hline 3 & 60 & 30 & 10 & 1350 & 0.51 \\
\hline 4 & 60 & 25 & 15 & 1350 & 0.5 \\
\hline 5 & 60 & 20 & 20 & 1350 & 0.49 \\
\hline 6 & 60 & 15 & 25 & 1350 & 0.47 \\
\hline 7 & 60 & 10 & 30 & 1350 & 0.46 \\
\hline 8 & 60 & 5 & 35 & 1350 & 0.43 \\
\hline 9 & 60 & 0 & 40 & 1350 & 0.42 \\
\hline
\end{tabular}

\begin{tabular}{|c|c|c|c|c|c|c|}
$\mathbf{2}$ & 3.02 & 3940 & 70 & 110 & 0.52 & 0.33 \\
\hline $\mathbf{3}$ & 3.02 & 3900 & 90 & 130 & 0.51 & 0.32 \\
\hline $\mathbf{4}$ & 3.02 & 3830 & 110 & 140 & 0.5 & 0.325 \\
\hline $\mathbf{5}$ & 3.02 & 3770 & 120 & 150 & 0.49 & 0.335 \\
\hline $\mathbf{6}$ & 3.01 & 3710 & 120 & 160 & 0.47 & 0.345 \\
\hline $\mathbf{7}$ & 3.01 & 3680 & 125 & 170 & 0.46 & 0.376 \\
\hline $\mathbf{8}$ & 3.01 & 3650 & 125 & 180 & 0.43 & 0.42 \\
\hline $\mathbf{9}$ & 3 & 3630 & 130 & 180 & 0.4 & 0.45 \\
\hline
\end{tabular}


From Table 7 we have found that the density of cement formulated with combination of F.Lime and PN decrease as a function of the increase in mass fraction of these admixtures. This decrease is generally due to the density of these admixtures, for pozzolan is $2.81 \mathrm{~g} . \mathrm{cm}^{-3}$, while that of limestone

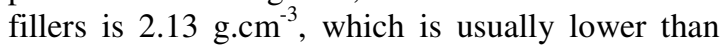
that of cement. We have noticed that the fineness by the specific surface (Blaine) of cement formulated in combination of F.Lime and PN increases with the increase in mass fraction of these additions. This increase is mainly due to the fineness of F.Lime which is $4776 \mathrm{~cm}^{2} . \mathrm{g}^{-1}$ and that of $\mathrm{PN}$ is $4576 \mathrm{~cm}^{2} \cdot \mathrm{g}^{-1}$. We observed that the initial and final setting times decrease with $(40 \%)$ of addition of F.Lime. This decrease is due on one hand to the chemical and mineralogical compositions of these fillers which are rich in $\mathrm{CaO}$ and poor in $\mathrm{Al}_{2} \mathrm{O}_{3}$ (physicochemical effect) and on the other hand is due to the fineness of these fillers which fills the voids between cement particles and that of aggregate (granular effect) "(F.Lime gives our material the role of setting accelerator). Subsequently, the setting time increased considerably with the increase in pozzolan content and the decrease in F.Lime proportion. This increase in setting time is generally due to the chemical and mineralogical compositions of NP

\subsection{Influence on compressive strength}

The Figure 3 illustrates the compressive strength of mortar or concrete formulated by combination of F.Lime and PN as a function of the mass fraction of these admixtures.

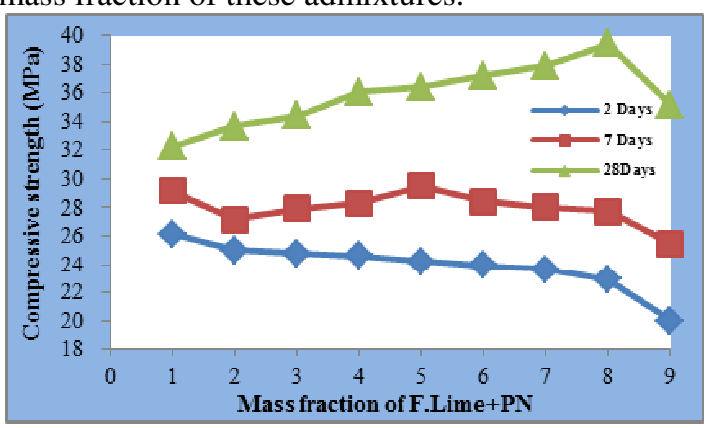

Figure 3: Compressive strength of mortar or concrete

At the Figure 3, we have noted that the compressive strengths at the young age (2 days), the middle ages ( 7 days) and the long-term ( 28 days) of all the mortars formulated by the

\subsection{Improvement of physical properties and mechanical performance}

In order to improve the physical properties and mechanical performance of mortar or concrete formulated by the combination between the F.Lime and the PN, we have incorporated into the different formulation matrix the admixtures of superplasticizers of high water reducer and setting aSP103 with $2.5 \%$ by weight of cement. which is very rich in aluminum oxide $(16.16 \%$ $\left.\mathrm{Al}_{2} \mathrm{O}_{3}\right)$ and silicon dioxide $\left(41.43 \% \mathrm{SiO}_{2}\right)$ and low $\left.\begin{array}{llll}\text { in an oxide of calcium }(8.8 \% & \mathrm{CaO}\end{array}\right)$, (physicochemical effect). These compositions promote the pozzolanic reaction which occurs between the reactive silica of $\mathrm{NP}$ and that of calcium hydroxide $\mathrm{Ca}(\mathrm{OH})_{2}$ released by cement during the hydration of mixture, which slows down the hydration phenomena. (PN gives our material the role of setting retarder). We also found that the W/C ratio of cement paste formulated by combination of F.Lime and PN decreased with increasing in PN proportion and decreased in F.Lime content. Indeed, when the water reacts chemically with the lime released by cement during the hydration of mixture, the water will be absorbed slowly form calcium hydroxide $\mathrm{Ca}(\mathrm{OH})_{2}$ on one hand. On the other hand, the decrease is generally due to the chemical and mineralogical compositions of these additions ( $\mathrm{PN}$ is poor in $\mathrm{CaO}$, despite, and limestone fillers are rich in $\mathrm{CaO}$ ). Finally, we distinguished that the expansion of cement paste formulated with combination of F.Lime and PN increases slightly as a function of the mass fraction of these additions. This increase does not exceed the limit ( $5 \mathrm{~mm}$ ) given by standard NF EN 196-3 + A1.

combination of F.Lime and PN increase steadily with age and show no fall. However, the compressive strengths decrease slightly with the addition of $40 \%$ of F.Lime. This decrease is generally due to the chemical and mineralogical compositions of F.Lime which is rich in $\mathrm{CaO}$. Then, the compressive strengths are increased with increasing the mass fraction of natural pozzolan and decreasing the proportion of fillers in the formulation matrix. This increase in compressive strength is explained by the fact that the interaction of reactive silica found in the vitreous part of $\mathrm{PN}$ and calcium hydroxide $\mathrm{Ca}(\mathrm{OH})_{2}$ released by cement during the hydration mixture, promotes the physicochemical effect of this addition and to contribute of consumption of lime present in cement by subsequently improving the compressive strength.

The Figure 4 illustrates the porosity of concrete formulated by the combination between F.Lime and $\mathrm{PN}$ as a function of the mass fraction of these additions in the presence of superplasticizer SP103.

\subsubsection{Influence on porosity}




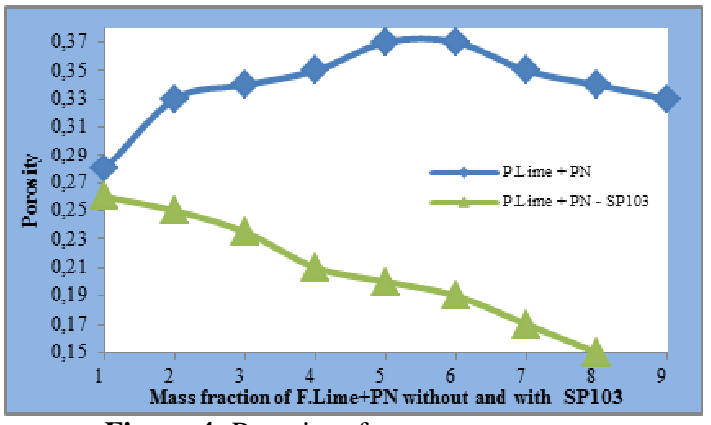

Figure 4: Porosity of mortar or concrete

From the Figure 4, we have found that the porosity of concrete formulated by the combination between of F.Lime, PN, and superplasticizers SP103 increases slightly according to their different percentages. In the second (F.Lime+PN-SP103), we observed a strong decrease in porosity. This decrease is due to the effect of combination of the organic admixtures of superplasticizers SP103 and inorganic admixtures (F.Lime $+\mathrm{PN}$ ) which disperse the cement grains from one another. On the other hand, it can be explained by the fact that the combination of F.Lime and PN (very fine material) in the presence of superplasticizers fill interstitial voids; between the cement and aggregate particles; (Physicochemical and microstructure effects).

\subsubsection{Influence on capillary absorption}

The Figure 5 shows the capillary absorption of concrete formulated by the combination of F.Lime and $\mathrm{PN}$ as a function of the mass fraction of these additions in the presence of superplasticizers SP103.

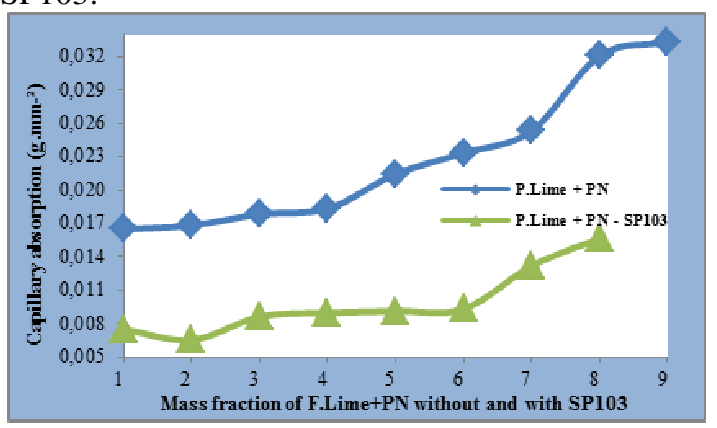

Figure 5: Capillary absorption of mortar or concrete

From the Figure 5, we have observed that the capillary absorption of concrete formulated by the combination between F.Lime and PN (P.Lime + $\mathrm{PN}$ ) increases with respect to the control mortar. On the other hand, we have found that the incorporation of superplasticizers in the concrete formulation matrix based on combination of F.Lime and the PN (P.Lime + PN-SP103) decreases the capillary absorption. This decrease can be explained on one hand by the fact that the capillary absorption of mortar is influenced by the porous structure and the level of superplasticizers. The latter can contribute to the reduction of the capillarity by the formation of a polymer film and reduce the capillary pressure. On the other hand, it is linked to the initial role of superplasticizers which disperses the cement grains from each other and also due to the fineness of these additions
$($ P.Lime + PN) which fill the voids between the particles by subsequently participating in the reduction of the capillary absorption of the concrete in the hardened state.

\subsubsection{Influence on mechanical performance}

The Figure 6 shows the evolutions of the compressive strength of mortar or concrete formulated by the combination between the F.Lime and the PN in the presence of superplasticizers SP103.

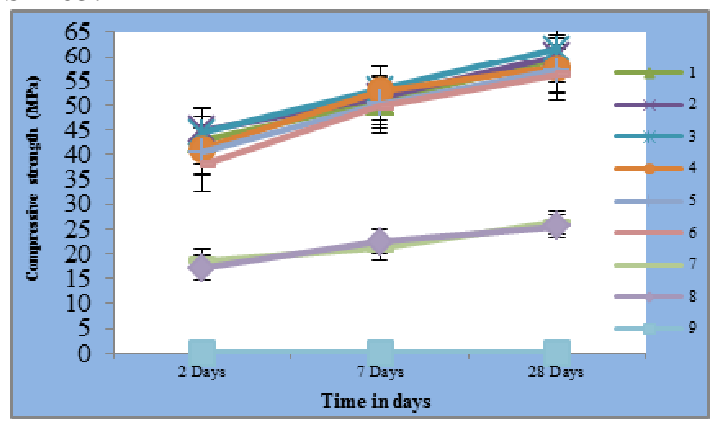

Figure 6: Compressive strength of mortar or concrete with SP103

From the Figure 6, we found that the compressive strengths of all the mortars formulated by the combination between the F.Lime and the PN in combination with superplasticizers SP103 increase steadily and show no drop. These increases can be explained by the fact that the combination between F.Lime and PN (very fine material) with their fine fills fill voids between the cement particles and granules (granular effect) on one hand. And on the other hand, the increases are related to the role of the addition of superplasticizers SP103 which disperse the cement grains from one another (physicochemical effects). In fact, when the organic molecules of SP103 are introduced into a suspension of cementitious material formulated by the combination between F.Lime and PN, a large part of them is fixed by adsorption to the surface of the cement particles (physicochemical and microstructural effect). The latter reduces the attractive forces of interaction between the particles and the atoms of different constituents (possibly chemical effects). The admixture of superplasticizer SP103 by their chemical effects modifies the interparticle forces, that is to say, to minimize the porosity by influencing the increase in the compressive strength.

\subsection{Gain in compressive strength at 28 days}

We also calculated the gain in compressive strength at 28 days, Figure 6, of mortar or concrete formulated by the combination between the F.Lime and the PN with and without superplasticizers SP103. 


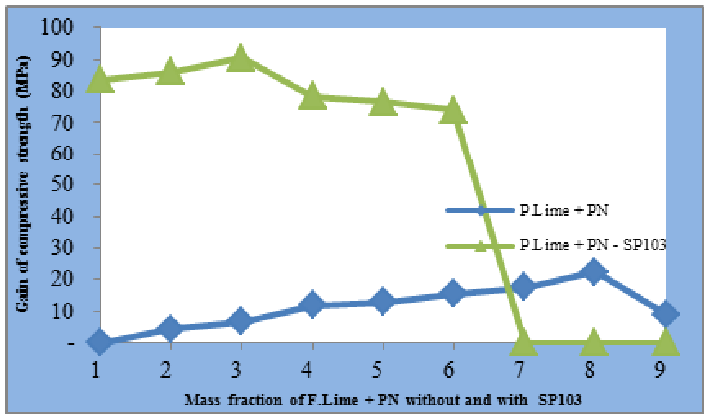

\section{Conclusion}

In this work, we studied the influence of partial substitution of clinker by combination of limestone fillers and natural pozzolan (P.Lime + PN) at $40 \%$ by weight of cement with a step of $5 \%$ in the presence of superplasticizers of high water reducer accelerator setting SP103. The influences of incorporation of these additions on physical and mechanical properties of fresh cement paste and mortar or concrete in hardened state were studied.

The obtained results from the various formulation elaborate shows that granular, physicochemical and microstructural effects have been distinguished. These effects influence the physical-chemical and mechanical properties, namely the reduction of the quantity of water used. Similarly, the density and the expansion have been decreased. In addition, the fineness by surface area Acknowledgments- The authors are pleased to acknowledge all engineers and employees of the laboratory of cement and quality control of Amran

\section{References}

1. M. H. Khudhair, M. S. Elyoubi, A. Elharfi, J. Mater. Environ. Sci. 8.3, 902-910 (2017).

2. M. H. Khudhair, M. S. Elyoubi, A. Elharfi, J. Mater. Environ. Sci .8.6, 1978-1989 (2017).

3. M. H. Khudhair, M. S. Elyoubi, A. Elharfi, Moroc. J. Chem. 5.1, 153-163 (2017).

4. M. H. Khudhair, A. Elharfi Int. J. ChemTech Res. 9.12, 695-704 (2016).

5. M. H. Khudhair, M. S. Elyoubi, and A. Elharfi, J. Mater. Environ. Sci. 8.11, 3973-3985 (2017).

6. M. H. R. Khudhair, M. S. Elyoubi, A.Elharfi, Mor. J. Chem. 5.3, 493-504 (2017).

7. M. S. Elyoubi, A.Elharfi, J. Chem. Technol. Metallo. 52.5, 873-884 (2017).

8. R. Chaid, R. Jauberthie, J. Zeghiche, and F. Kherchi, Eur. J. Environ. Civ. Eng. 15.3, 427-445 (2011).

9. G. C. Isaia, A. L. G. GASTALDInI, and R. Moraes, Cem. Concr. Compos. 25.1, 69-76 (2003).

10. R. L. Day and C. Shi, Cem. Concr. Res. 24.8, 14851491 (1994).

11. V. Sata, C. Jaturapitakkul, and K. Kiattikomol, Constr. Build. Mater. 21.7, 1589-1598 (2007).

12. M. H. Khudhair, M. S. Elyoubi, A. Elharfi ,Res. J. Pharm. Biol. Chem. Sci. 8.3, 1698-1712 (2017).

13. M. H. R. Khudhair, B. Elhilal, M, S, Elyoubi, and A. Elharfi, J. Mater. Environ. Sci. 8.7, 2302-2310 (2017).

14. C. Autier, N. Azema, J.-M. Taulemesse, and L. Clerc, Powder Technol. 249, 282-289 ( 2013).

15. M. Khudhair, and A. Elharfi. Éditions Universitaires Européennes, (2017).

16. M.-H. Zhang, K. Sisomphon, T. S. Ng, and D. J. Sun, Constr. Build. Mater. 24.9, 1700-1707 (2010).
Figure 7: Gain in compressive strength at 28 days

From the Figure 7, we observed that the combination between of F.Lime and PN in the mortar or concrete matrix with superplasticizers SP103 improves the compressive strength.

and setting time were increased. We found that the porosity and the capillary absorption were decreased (granular and microstructural effects). However, we have observed that the compressive strengths at young ages (2 days), medium ages (7 days) and long-term (28 days) have been improved in the presence of superplasticizers compared to the controls (physical-chemical and mechanical).

Our study contributes to valorize of mineral and natural resources such as natural pozzolan $(\mathrm{PN})$ and limestone fillers (P-Lime) in Amran-region of Yemen, to minimize the greenhouse gas emissions, to reduce the energy and the raw material consumption, and to manufacture of a new ecological hydraulic binder and durable; with physiccochemical and mechanical properties improved.

Cement plant of Yemen for providing the facilities for the research.

17. Y. L. Yaphary, Z. Yu, R. H. Lam, and D. Lau, Constr. Build. Mater. 141, 94-103 (2017).

18. M. H. Khudhair, M. S. Elyoubi, and A. Elharfi, J. Mater. Environ. Sci. 9.1 (2018) 56-65.

19. O. Boukendakdji, E.-H. Kadri, and S. Kenai, Cem. Concr. Compos. 34.4, 583-590 (2012).

20. J. Baron, J. Olivier, And J. Weiss,. Ed. Eyrolles. 806 (1997).

21. M. Cyr, P. Lawrence, E. Ringot, and A. CarlesGibergues, Mater. Struct. 33.7, 466-472 (2000).

22. O. Gheevarhese, C. A. Strydom, J. H. Potgieter, and S. S. Potgieter, Water SA. 28.1, 45-48 (2002).

23. J. Lanas and J. I. Alvarez-Galindo, Cem. Concr. Res.33.11, 1867-1876 (2003).

24. Y. Benachour, C. A. Davy, F. Skoczylas, and H. Houari, Cem. Concr. Res.38.6, 727-736 (2008).

25. C. Glotzbach, D. Stephan, and M. Schmidt, Cem. Concr. Compos.36, 42-47 (2013) 